\title{
Major changes in Medicare billing are planned for January 2021: Some specialties fare better than others
}

\author{
The changes decrease Medicare payments for procedural services \\ but increase valuation of office-based services
}

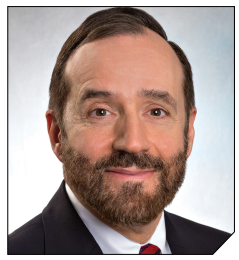

\author{
Robert L. Barbieri, MD \\ Editor in Chief, OBG MANAGEMENT \\ Chair, Obstetrics and Gynecology \\ Brigham and Women's Hospital \\ Boston, Massachusetts \\ Kate Macy Ladd Professor of Obstetrics, \\ Gynecology and Reproductive Biology \\ Harvard Medical School
}

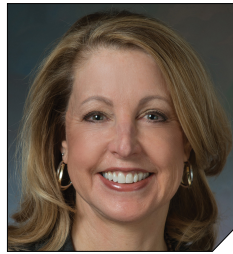

\author{
Barbara Levy, MD \\ Clinical Professor, Obstetrics and Gynecology \\ The George Washington University School \\ of Medicine and Health Sciences \\ Washington, DC \\ Member, OBG MANAGement Board of Editors
}

D he Centers for Medicare and Medicaid Services (CMS) finalized an increase in the relative value of evaluation and management (E/M) service codes effective January 1,2021 , which results in an overall decrease in the payment for procedural services in the Medicare program. (Due to the mandate for budget neutrality, an increase in relative value units [RVUs] for $\mathrm{E} / \mathrm{M}$ resulted in a large decrease in the conversion factor-the number of dollars per RVU). This has increased payments for endocrinologists, rheumatologists, and family medicine clinicians and decreased payments for radiologists, pathologists, and surgeons.

In a major win for physicians, CMS proposes to simplify documentation requirements for billing and focus on the complexity of the medical decision making (MDM) or the total time needed to care for the patient on the date of the service as the foundation for determining the relative value of the service. Therefore, there is no more counting bullets-ie, we don't have to perform a comprehensive physical exam or review of systems to achieve a high level code! Prior to this change, time was only available for coding purposes when counseling and coordination of care was the predominant service ( $>50 \%)$, and only face-to-face time with the patient was considered. Effective January 1, for office and other outpatient services, total time on the calendar date of the encounter will be used. This acknowledges the intensity and value of nonface-to-face work.

Acting through CMS, the federal government influences greatly the US health care system. CMS is an agency in the Department of Health and Human Services that administers the Medicare program and partners with state governments to administer the Health Insurance Exchanges, Medicaid, and the Children's Health Insurance programs (CHIP). ${ }^{1}$ In addition, CMS is responsible for enforcing quality care standards in long-term care facilities and clinical laboratories and the implementation of the Health Insurance Portability and Accountability Act. ${ }^{1}$

In January, CMS plans the following major changes to coding and documentation $^{2,3}$ :
1. Selection of the level of E/M service will no longer require documentation of bullet points in the history, physical exam, and MDM. The simplified system allows physicians and qualified health care professionals to code either by total time (both face-to-face and non-face-to-face) on the date of the encounter or by level of MDM.

2. For established office patients, 5 levels of office-based evaluation and management services will be retained. CMS had initially proposed to reduce the number of office-based E/M codes from 5 to 3 , combining code levels 2,3 , and 4 into 1 code. ${ }^{4}$ However, after receiving feedback from professional societies and the public, CMS abandoned the plan for radical simplification of coding levels. ${ }^{2,3}$ Implementation of their proposal would have resulted in the same payment for treatment of a hang nail as for a complex gyn patient with multiple medical problems. Both patient advocacy groups and professional societies argued

doi: 10.12788 /obgm.0028 
that incentives originally were misaligned.

3. For new office patients, since both 99201 and 99202 require straightforward MDM, the level 1 code (99201) has been eliminated, reducing the number of code levels from 5 to 4 .

4. History and physical exam will no longer be used to determine code level for office $\mathrm{E} / \mathrm{M}$ codes. These elements will be required only as medically appropriate. This means that documentation review will no longer focus on "bean counting" the elements in the history and physical exam.

5. Following a reassessment of the actual time required to provide $\mathrm{E} / \mathrm{M}$ services in real-life practice, CMS plans to markedly increase the relative value of office visits for established patients and modestly increase the relative value of office visits for new patients. CMS operates under the principle of "neutral budgeting," meaning that an increase of the relative value of $\mathrm{E} / \mathrm{M}$ codes will result in a decrease in the payment for procedural codes. The actual RVUs for procedural services do not change; however, budget neutrality requires a decrease in the dollar conversion factor. The proposed changes will increase the payment for $\mathrm{E} / \mathrm{M}$ services and decrease payments for procedural services.

\section{Refocusing practice on MDM complexity}

The practice of medicine is a calling with great rewards. Prominent among those rewards are improving the health of women, children, and the community, developing deep and trusting relationships with patients, families, and clinical colleagues. The practice of medicine is also replete with a host of punishing administrative burdens, including prior authorizations, clunky electronic medical records, poorly designed quality metrics that are applied to clinicians, and billing compliance rules that emphasize the repetitive documentation of clinical information with minimal value.

Some of the most irritating aspects of medical practice are the CMS rules governing medical record documentation required for billing ambulatory office visits. Current coding compliance focuses on counting the number of systems reviewed in the review of systems; the documentation of past history, social history, and family history; the number of organs and organ elements examined during the physical examination; and the complexity of MDM.

In January 2021, CMS plans to adopt new Current Procedural Terminology (CPT) code descriptors for the office and other outpatient $\mathrm{E} / \mathrm{M}$ services that sunset most of the "bean-counting" metrics and emphasize the importance of the complexity of MDM in guiding selection of a correct code. ${ }^{2}$ Beginning in January 2021, clinicians will have the option of selecting an E/M code level based on the total amount of time required to provide the office visit service or the complexity of MDM. When selecting a code level based on MDM the new guidance emphasizes the importance of reviewing notes from other clinicians, reviewing test results, ordering of tests, and discussing and coordinating the care of the patient with other treating physicians. These changes reflect a better understanding of what is most important in good medical practice, promoting better patient care. TABLES 1 (page 12) AND 2 (page 14) provide the initial guidance from CMS concerning selection of $\mathrm{E} / \mathrm{M}$ code level based on time and MDM, respectively. ${ }^{2}$ The guidance for using MDM to select an E/M code level is likely to evolve following implementation, so stay tuned. When using MDM to select a code, 2 of the 3 general categories are required to select that level of service.

\section{Increase in the valuation of office-based E/M services}

The Medicare Physician Fee Schedule uses a resource-based relative value system to determine time and intensity of the work of clinical practice. This system recognizes 3 major factors that influence the resources required to provide a service:

- work of the clinician

- practice expense for technical components

- cost of professional liability insurance.

Many primary care professional associations have long contended that CMS has undervalued office-based $\mathrm{E} / \mathrm{M}$ services relative to procedures, resulting in the devaluing of primary care practice. After the CPT code descriptors were updated by the CPT editorial panel, 52 specialty societies surveyed their members to provide inputs to CMS on the time and intensity of the office and other outpatient $\mathrm{E} / \mathrm{M}$ codes as currently practiced. The American Medical Association's Specialty Society Resource-Based Relative Value Scale Update Committee (RUC) reviewed the surveys and provided new inputs via open comment to CMS. CMS has responded to this feedback with a review of the intensity of clinical work required to provide an ambulatory visit service. In response to the review, CMS proposes to accept the recommendations of the RUC representing the house of medicine and increase the work and practice expense relative value assigned 
to new and established office visit codes. Overall, the combination of changes in relative values assigned for the work of the clinician and the expense of practice, increases the total value of office-based $\mathrm{E} / \mathrm{M}$ codes for new patients by $7 \%$ to $14 \%$ and for established patients from $28 \%$ to $46 \%$ (see supplemental table, page E1).

\section{Decreased payments for procedural services}

Medicare is required to offset increased payment in one arena of health care delivery with decreased payment in other arenas of care, thereby achieving "budget-neutrality." As detailed above, CMS plans to increase Medicare payments for office-based $\mathrm{E} / \mathrm{M}$ services. Payment for services is calculated by multiplying the total RVUs for a particular service by a "conversion factor" (ie, number of dollars per RVU). To achieve budget-neutrality, CMS has proposed substantially reducing the conversion factor for 2021 (from $\$ 36.09$ to \$32.26), which will effectively decrease Medicare payments for procedural services since their RVUs have not changed. While the AMA RUC and many specialty societies continue to strongly advocate for the $\mathrm{E} / \mathrm{M}$ work RVU increases to be included in the $\mathrm{E} / \mathrm{M}$ components of 10- and 90-day global services, CMS has proposed to implement them only for "stand alone" E/M services.

Organizations are lobbying to delay or prevent the planned decrease in conversion factor, which results in substantial declines in payment for procedural services. (See "What do the Medicare billing changes mean for the Obstetrical Bundled services?" with the online version of this article.) Due to the economic and clinical

TABLE 1 Current Procedural Terminology code descriptors for selecting office-based evaluation and management level based on time ${ }^{2}$

\begin{tabular}{l|l}
\hline New patients - Code levels & Time \\
\hline 99202 & 15 to 29 minutes \\
\hline 99203 & 30 to 44 minutes \\
\hline 99204 & 45 to 59 minutes \\
\hline 99205 & 60 to 74 minutes \\
\hline Established patients -Code levels & Time \\
\hline 99211 & $\begin{array}{l}\text { Presenting problem is minimal, } \\
<10 \text { minutes }\end{array}$ \\
\hline 99212 & 10 to 19 minutes \\
\hline 99213 & 20 to 29 minutes \\
\hline 99214 & 30 to 39 minutes \\
\hline 99215 & 40 to 54 minutes \\
\hline
\end{tabular}

practice challenges caused by the coronavirus disease 2019 (COVID-19) pandemic it would be best if CMS did not reduce payments to physicians who are experts in procedural health care, thereby avoiding the risk of reduced access to these vital services.

If the current CMS changes in payment are implemented, endocrinologists, rheumatologists, and family physicians will have an increase in payment, and radiologists, pathologists, and surgeons will have a decrease in payment (TABLE 3 , page 43). ${ }^{6}$ Obstetrics and gynecology is projected to have an $8 \%$ increase in Medicare payment. However, if an obstetrician-gynecologist derives most of their Medicare payments from surgical procedures, they are likely to have a decrease in payment from Medicare. Other payers will be incorporating the new coding structure for 2021; however, their payment structures and conversion factors are likely to vary. It is important to note that the RVUs for procedures have not changed. The budget neutrality adjustment resulted in a much lower conversion factor and therefore a decrease in payment for those specialties whose RVUs did not increase.

\section{Bottom line}

Working through the Medicare, Medicaid, and CHIP programs, CMS can influence greatly the practice of medicine including medical record documentation practices and payment rates for every clinical service. CMS proposes to end the onerous "bean counting" approach to billing compliance and refocus on the complexity of MDM as the foundation for selecting a billing code level. This change is long overdue, valuing the effective management of complex patients in office practice. Hopefully, CMS will reverse the planned reduction in the payment for procedural services, preserving patient access to important health care services.

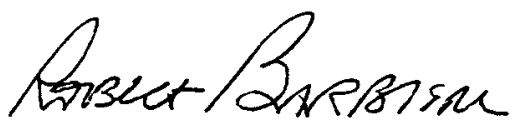

RBARBIERI@MDEDGE.COM

The authors report no financial relationships relevant to this article. 


\section{TABLE 2 Centers for Medicare and Medicaid Services guidance for selecting office-based evaluation and management level-based medical decision making (MDM) ${ }^{2}$}

\begin{tabular}{|c|c|c|c|c|}
\hline Code & Level of MDM & $\begin{array}{l}\text { Number and complexity } \\
\text { of problems addressed }\end{array}$ & $\begin{array}{l}\text { Amount and complexity of } \\
\text { data to be reviewed and } \\
\text { analyzed }\end{array}$ & $\begin{array}{l}\text { Risk of complications and } \\
\text { morbidity or mortality }\end{array}$ \\
\hline $\begin{array}{l}99202 \\
99212\end{array}$ & Straightforward & $\begin{array}{l}\text { Minimal: self-limited or } \\
\text { minor problem }\end{array}$ & Minimal or none & $\begin{array}{l}\text { Minimal risk of morbidity } \\
\text { from testing or treatment }\end{array}$ \\
\hline $\begin{array}{l}99203 \\
99213\end{array}$ & Low & $\begin{array}{l}\text { - } 2 \text { or more self-limited or } \\
\text { minor problems } \\
\text { - Or } 1 \text { stable chronic } \\
\text { illness } \\
\text { - Or } 1 \text { acute } \\
\text { uncomplicated illness or } \\
\text { injury }\end{array}$ & $\begin{array}{l}\text { - Must meet criteria in either } \\
\text { category } \\
\text { - Category 1: Any } \\
\text { combination of } 2 \text { : } \\
\text { - Review of external note(s), } \\
\text { - Review of result(s) of tests, } \\
\text { - Ordering of tests } \\
\text { - Category 2: Assessment } \\
\text { requiring an independent } \\
\text { historian }\end{array}$ & $\begin{array}{l}\text { Low risk of morbidity from } \\
\text { additional diagnostic testing } \\
\text { or treatment }\end{array}$ \\
\hline $\begin{array}{l}99204 \\
99214\end{array}$ & Moderate & $\begin{array}{l}\text { - } 1 \text { or more chronic } \\
\text { illnesses with } \\
\text { exacerbation or side } \\
\text { effects of treatment } \\
\text { - Or } 2 \text { or more stable } \\
\text { chronic illnesses } \\
\text { - Or } 1 \text { undiagnosed new } \\
\text { problem with uncertain } \\
\text { prognosis } \\
\text { - Or } 1 \text { acute illness with } \\
\text { systemic symptoms } \\
\text { - Or } 1 \text { acute complicated } \\
\text { injury }\end{array}$ & $\begin{array}{l}\text { - Must meet criteria in one of } \\
\text { the } 3 \text { categories below: } \\
\text { - Category 1: Meets } 3 \text { of } 4 \text { : } \\
\text { review of external notes, } \\
\text { review of results, ordering } \\
\text { of tests, assessment } \\
\text { requiring an independent } \\
\text { historian. } \\
\text { - Category 2: Independent } \\
\text { interpretation of a test. } \\
\text { - Category 3: Discussion } \\
\text { of management or test } \\
\text { interpretation with external } \\
\text { physician or other clinician }\end{array}$ & $\begin{array}{l}\text { - Moderate risk of morbidity } \\
\text { from additional diagnostic } \\
\text { testing or treatment. } \\
\text { - Examples: } \\
\text { - Prescription drug } \\
\text { management } \\
\text { - Decisions regarding minor } \\
\text { surgery with identified } \\
\text { patient or procedure risk } \\
\text { factors } \\
\text { - Decision regarding } \\
\text { elective major surgery } \\
\text { without documented risk } \\
\text { factors } \\
\text { - Diagnosis or treatment } \\
\text { significantly limited by } \\
\text { social determinants of } \\
\text { health }\end{array}$ \\
\hline $\begin{array}{l}99205 \\
99215\end{array}$ & High & $\begin{array}{l}1 \text { or more chronic } \\
\text { illnesses with severe } \\
\text { exacerbation, } \\
\text { progression or side } \\
\text { effects of treatment } \\
\text { - Or } 1 \text { acute or chronic } \\
\text { illness or injury that } \\
\text { poses a threat to life or } \\
\text { bodily function }\end{array}$ & $\begin{array}{l}\text { - Must meet criteria in one } \\
\text { category } \\
\text { - Category 1: Meets } 3 \text { of } 4 \text { : } \\
\text { review of external notes, } \\
\text { review of results, ordering } \\
\text { of tests, assessment } \\
\text { requiring an independent } \\
\text { historian. } \\
\text { - Category 2: Independent } \\
\text { interpretation of a test. } \\
\text { - Category 3: Discussion } \\
\text { of management or test } \\
\text { interpretation with external } \\
\text { physician or other clinician }\end{array}$ & $\begin{array}{l}\text { - High risk of morbidity } \\
\text { from additional diagnostic } \\
\text { testing or treatment. } \\
\text { - Examples: } \\
\text { - Drug therapy requiring } \\
\text { intensive monitoring for } \\
\text { toxicity } \\
\text { - Decision regarding } \\
\text { elective major surgery } \\
\text { with documented risk } \\
\text { factors } \\
\text { - Decision regarding } \\
\text { emergency major surgery } \\
\text { - Decision regarding } \\
\text { hospitalization } \\
\text { - Decision not to resuscitate }\end{array}$ \\
\hline
\end{tabular}




\section{EDITORIAL}

CONTINUED FROM PAGE 14

TABLE 3 Projected changes in Medicare payments with the new CMS rules in January 2021, a

\begin{tabular}{l|c}
\hline Specialties with greatest payment increase & Percent increase \\
\hline Endocrinology & $+17 \%$ \\
\hline Rheumatology & $+16 \%$ \\
\hline Hematology/Oncology & $+14 \%$ \\
\hline Family Practice & $+13 \%$ \\
\hline Allergy/lmmunology & $+9 \%$ \\
\hline Obstetrics and Gynecology & $+8 \%$ \\
\hline Psychiatry & $+8 \%$ \\
\hline Specialties with greatest payment decrease & $-11 \%$ \\
\hline Radiology & $-9 \%$ \\
\hline Pathology & $-9 \%$ \\
\hline Cardiac Surgery & $-9 \%$ \\
\hline Interventional Radiology & $-8 \%$ \\
\hline Anesthesiology & $-8 \%$ \\
\hline Thoracic Surgery & $-7 \%$ \\
\hline General Surgery & Percent decrease \\
\hline aThe estimated changes are based on the summation of changes in the assigned relative value for clinical work, \\
practice expense, and professional liability expense.
\end{tabular}

\section{References}

1. Centers for Medicare and Medicaid Services. https://www.cms.gov/. Accessed August 28, 2020.

2. American Medical Association. CPT Evaluation and Management (E/M) Office or Other Outpatient (99202-99215) and Prolonged Services (99354, 99355, 99356, 99XXX) Code and Guideline Changes. 2019. https://www.ama-assn.org /system/files/2019-06/cpt-office-prolonged-svs -code-changes.pdf. Accessed August 28, 2020.

3. The American Academy of Family Physicians. Family medicine updates. Ann Fam Med. 2020;18:84-85. doi: 10.1370/afm.2508.

4. Centers for Medicare and Medicaid Services. Final policy, payment and quality provisions changes to the Medicare Physician Fee Schedule for calendar year 2019. November 1, 2018. https://www.cms.gov/newsroom/fact-sheets /final-policy-payment-and-quality-provisionschanges-medicare-physician-fee-schedulecalendar-year. Accessed August 28, 2020.

5. Department of Health and Human Services; Centers for Medicare and Medicaid Services. 42 CFR Parts 410, 414, 415, 423, 424, and 425. Federal Register. 2020;85(159). https://www.govinfo.gov /content/pkg/FR-2020-08-17/pdf/2020-17127 .pdf. Accessed August 28, 2020. 


\section{What do the Medicare billing changes mean for the Obstetrical Bundled services?}

The CY 2020 Medicare Physician Fee Schedule Final Rule was published electronically in the Federal Register on November 1,2019 . This final rule aligns the evaluation and management $(E / M)$ coding and payment with changes recommended by the Current Procedural Terminology (CPT) Editorial Panel and American Medical Association's (AMA) Specialty Society Resource-Based Relative Value Scale Update Committee (RUC) for office/outpatient E/M visits. Unfortunately, the Centers for Medicare and Medicaid Services (CMS) did not agree with the RUC, AMA, and specialty societies that the E/M payment changes should be applicable across all global services that incorporate E/M visits-despite the fact that the values proposed by the RUC incorporated survey data from 52 specialties, representing most of medicine (including those specialties that predominantly perform procedures). Specifically, CMS expressed the view that the number of E/M visits within the 10- and 90-day global codes, as well as the maternity care bundle, were difficult to validate; therefore, the increased values would not be distributed to those procedural services.

Many professional societies expressed significant concerns about the resulting budget neutrality adjustments that would occur effective January 2021. The great news for ObGyns is that the American College of Obstetricians and Gynecologists (ACOG) was able to respond directly to CMS's concerns with data to support the number of prenatal visits within the Obstetrical Bundle. Tapping into a de-identified, cloud-based data set of prenatal records - representing more than 1,100 obstetric providers with close to 30,000 recently completed pregnancies-ACOG was able to document both a mean and median number of prenatal visits across a broad geographic, payer, and patient demographic that supported the 13 prenatal visits in the Obstetrical Bundle.

With ACOG's advocacy and ability to provide data to CMS, the proposed physician fee schedule rule for 2021 has proposed to incorporate the E/M increased reimbursement into the prenatal care codes. Now we urge the CMS to finalize this proposal. Although Medicare pays for a tiny number of pregnancies annually, we hope that all payers, including Medicaid and managed care plans, will agree with this acknowledgement of the increased work of evaluation and management that obstetricians provide during prenatal care. Join ACOG in telling CMS to finalize their proposal to increase the values of the global obstetric codes: https://acog.quorum.us/campaign/28579/.

TABLE Work relative value unit (RVU) assignments for office-based evaluation and management codes ${ }^{1}$

\begin{tabular}{l|c|c|c}
\hline New patient code & $\begin{array}{c}\text { 2019 work } \\
\text { RVU }\end{array}$ & $\begin{array}{c}\text { 2021 work } \\
\text { RVU }\end{array}$ & $\begin{array}{c}\text { Percent } \\
\text { change }\end{array}$ \\
\hline 99201 & 0.48 & $\begin{array}{c}\text { No longer } \\
\text { utilized }\end{array}$ & - \\
\hline 99202 & 0.93 & 0.93 & $0 \%$ \\
\hline 99203 & 1.42 & 1.60 & $+14 \%$ \\
\hline 99204 & 2.43 & 2.60 & $+7 \%$ \\
\hline 99205 & 3.17 & 3.50 & $+10 \%$ \\
\hline Established & 2019 work & 2021 work & $\begin{array}{c}\text { Percent } \\
\text { change }\end{array}$ \\
\hline patient code & RVU & RVU & $0 \%$ \\
\hline 99211 & 0.18 & 0.18 & $+46 \%$ \\
\hline 99212 & 0.48 & 0.70 & $+34 \%$ \\
\hline 99213 & 0.97 & 1.30 & $+28 \%$ \\
\hline 99214 & 1.50 & 1.92 & $+33 \%$ \\
\hline 99215 & 2.11 & 2.80 & \\
\hline
\end{tabular}

1. American Osteopathic Association. CMS releases Medicare Physician Fee Schedule Final Rule for 2020. https://thedo.osteopathic.org/wp-content/uploads/2019/11/Physician-Fee-Schedule-2020.pdf. Accessed August 28, 2020. 